This item was submitted to Loughborough's Research Repository by the author.

Items in Figshare are protected by copyright, with all rights reserved, unless otherwise indicated.

\title{
Promoting battery testing in developing countries through development of a low-cost battery test system
}

PLEASE CITE THE PUBLISHED VERSION

https://doi.org/10.1109/IHTC53077.2021.9698932

PUBLISHER

IEEE

VERSION

AM (Accepted Manuscript)

\section{PUBLISHER STATEMENT}

Personal use of this material is permitted. Permission from IEEE must be obtained for all other uses, in any current or future media, including reprinting/republishing this material for advertising or promotional purposes, creating new collective works, for resale or redistribution to servers or lists, or reuse of any copyrighted component of this work in other works.

\section{LICENCE}

\section{All Rights Reserved}

\section{REPOSITORY RECORD}

Mbewe, Chrispin, Richard Blanchard, Gianfranco Claudio, Martin Bliss, Nigel Monk, and John Barton. 2022. "Promoting Battery Testing in Developing Countries Through Development of a Low-cost Battery Test System". Loughborough University. https://hdl.handle.net/2134/17161334.v1. 


\section{Promoting battery testing in developing countries through development of a low-cost battery test}

\section{system}

\author{
Chrispin Gogoda Mbewe \\ Centre for Renewable Energy Systems \\ Technology \\ Loughborough University \\ Loughborough, Leicestershire, UK \\ c.g.mbewe@lboro.ac.uk \\ Martin Bliss \\ Centre for Renewable Energy Systems \\ Technology \\ Loughborough University \\ Loughborough, Leicestershire, UK \\ m.bliss@1boro.ac.uk
}

\author{
Gianfranco Claudio \\ Centre for Renewable Energy Systems \\ Technology \\ Loughborough University \\ Loughborough, Leicestershire, UK \\ g.claudio@lboro.ac.uk \\ Nigel Monk \\ Centre for Renewable Energy Systems \\ Technology \\ Loughborough University \\ Loughborough, Leicestershire, UK \\ n.a.monk2@1boro.ac.uk
}

\author{
John Barton \\ Centre for Renewable Energy Systems \\ Technology \\ Loughborough University \\ Loughborough, Leicestershire, UK \\ j.p.barton@lboro.ac.uk \\ Richard Blanchard \\ Centre for Renewable Energy Systems \\ Technology \\ Loughborough University \\ Loughborough, Leicestershire, UK \\ r.e.blanchard@lboro.ac.uk
}

\begin{abstract}
Off-grid renewable energy electricity generation is a proven solution to meeting energy needs in situations such as a refugee camp and communities with no access to modern energy services. To overcome the problem of intermittence that is inherent in renewable energy resources, battery energy storage is used to store excess energy and release it when the renewable resource is insufficient. However, batteries, not only have a high upfront cost but are reported to be the leading cause of failure in renewable electricity generation systems. These are the major challenges facing low income countries in their efforts to increase access to clean energy. The situation requires a blend of localised solutions including meaningful battery testing that goes beyond measuring open circuit voltage which can only provide very limited information about performance and longevity of the batteries. Traditionally, battery test systems are expensive to buy, making it difficult for developing nations to actively participate in research by testing battery performance as well as help with detecting poor quality products that typically fail more quickly than expected. In this work, a low-cost battery test system was designed, developed, and implemented for lifecycle testing of three batteries at the same time.
\end{abstract}

Keywords-Energy access, renewable energy, intermittence, battery energy storage, test rig design, low-cost

\section{INTRODUCTION}

With 768 million people without access to electricity in 2021, off-grid renewable energy electricity generation continues to be a proven solution to improving electricity access to the underprivileged who are mostly concentrated in rural communities in developing countries and those in forced humanitarian emergencies due to natural disasters or conflicts [1]-[3]. Meanwhile, some 2.9 billion people across the globe continued to have no access to clean cooking in 2019 [4]. Both access to electricity and clean cooking were found to be some of the major challenges in refugee and internationally displaced persons camps, as well as in informal humanitarian settlements [1], [5]. With approximately 4 million deaths per year as a result of inhaling harmful substances from cooking with solid fuels and inefficient cookstoves, solar photovoltaic (PV) electric cooking (eCook) is one of the promising developments towards increasing access to clean cooking [6], [7]. To overcome the problem of intermittence, which is inherent in renewable energy resources, battery energy storage is used to store excess energy and release it when the renewable energy resource is in short supply [8], [9]. Therefore, the reliability of a clean energy system is directly linked to the quality and performance of the battery energy storage. This work was motivated by the need to promote localised battery testing for the eCook concept whose implementation targets the developing world but with performance of the batteries not clearly understood [7].

\section{PROBLEM}

Batteries for energy storage are considered the weakest link leading to early failure of renewable energy systems [10], [11]. This problem may be more significant for example in a battery-supported eCook where the relatively high power demanded [7], places heightened loads on batteries. Apart from high upfront cost, the need for frequent replacement of the batteries makes the system even more expensive to sustain [12]. Quick battery failure can be because of poor-quality products; incorrect details from suppliers, which can make a battery to be used the wrong way; abuse from users; and or adverse operating conditions.

Active state of the art research into battery performance is concentrated in the developed world. Some of the reasons are for example, the ongoing push for electrification of transport [10], ability to pay for expensive battery testing equipment and wide availability of expertise. This can mean some problems in developing nations are solved by chance from the output of the research activities in the developed world. For example, cost reduction in batteries because of active research in storage for electric vehicle currently popular in the developing world. This is expected to continue to help lowincome communities to afford lithium batteries that have traditionally been associated with cost disadvantage [13].

There is an increased recognition that the performance of batteries in a pack and under different applications substantially deviates from the results obtained at cell level characterisation or from those given by manufacturers. Battery pack testing may require test systems capable of handling high discharge current, such as that to expect from the fast-growing novel solar PV eCook concept [6], [7], to examine performance of batteries for example in the eCook conditions. Systems capable of handling these demands are usually custom-made and are therefore more expensive with long lead times [14]. This would be a challenge for countries characterised by very low budget to afford such equipment. 
To overcome the cost challenge, which links to the other challenges as above, the aim of this work was to develop a novel low-cost battery testing solution for promotion of battery research in the developing world. Specifically, the objectives were to conceptualise, design, construct and test the operation of the test system. The development of the test rig was done at the Centre for Renewable Energy Systems Technology (CREST) at Loughborough University.

\section{LOW-COST TEST RIG DEVELOPMENT}

\section{A. Technology overview and related work}

A typical battery test system involves two main processes of charging and discharging [15]-[17] which is a fundamental feature for any storage system [8], [9]. A block diagram shown in Fig. 1 represents an overview of the operating procedure for the developed test system.

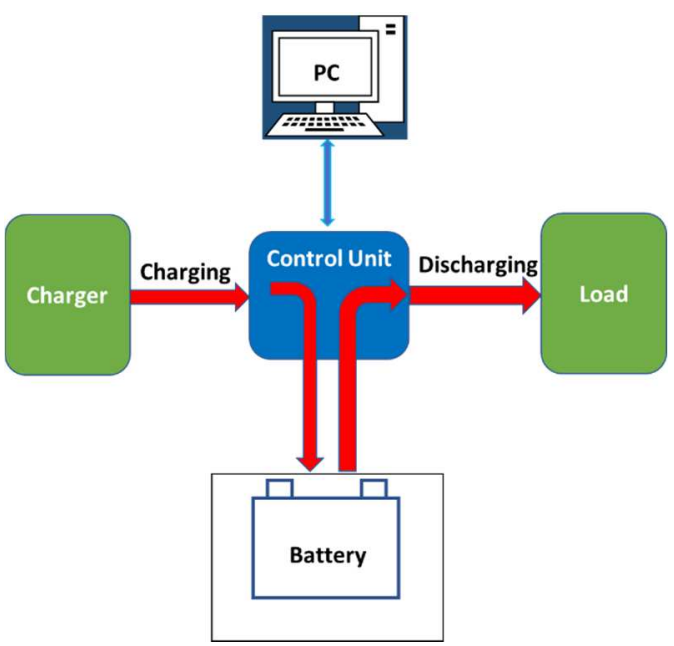

Fig. 1: Overview operating procedure for the developed battery test system

The charger can be a bench power supply, a solar PV module or a charger specified or allowed by the manufacturer. The load can be anything that draws current from the battery to deliver a particular task. Alternatively, an electronic load can be used to provide a controlled discharge depending on what is being tested. The control unit comprises a microprocessor, transducers and switching mechanisms between the charger, load, and the battery. The battery is the unit under test while the computer provides a platform for running a software that interacts with the control unit, electronic load, power supplies, data loggers and battery where a communication protocol exists.

Similar initiatives have been developed in the past [15], [17] but with a focus on the test automation and in fast charging applications [16]. This work, however, goes beyond automation by focusing on cost reduction approaches similar to $[18]$ in their work on a flywheel energy storage test rig.

\section{B. Concept design and development}

The original prototype used an Arduino Uno Microcontroller to automatically control charge and discharge circuitry with the aid of a 4-channel Arduino Relay Module. Arduino programming was utilised to write a program code using an Arduino Integrated Development Environment which was uploaded on the micro-controller for execution.

To test the operation of the code, an EA-PS 3032- 10 B DC Power Supply was employed to mimic the behaviour of a battery under test by increasing and decreasing the supply voltage for charging and discharging, respectively. An electronic load was used to mimic battery discharging and the capacity measurement by the electronic load was used to validate the capacity value recorded by the Arduino.

The prototype shown in Fig. 2, was able to run charge and discharge cycles as expected, however, the following challenges were observed:

(i) It was difficult to integrate other instruments into the Arduino software package thereby limiting automation capabilities.

(ii) Re-routing of events was also difficult, affecting integration of automated battery cycling and periodic capacity testing into one package.

(iii) It was observed that there was little prospect of increasing the number of channels on the test rig.

(iv) Relays on the Arduino module were limited to $10 \mathrm{~A}$ thereby limiting the testing capabilities.

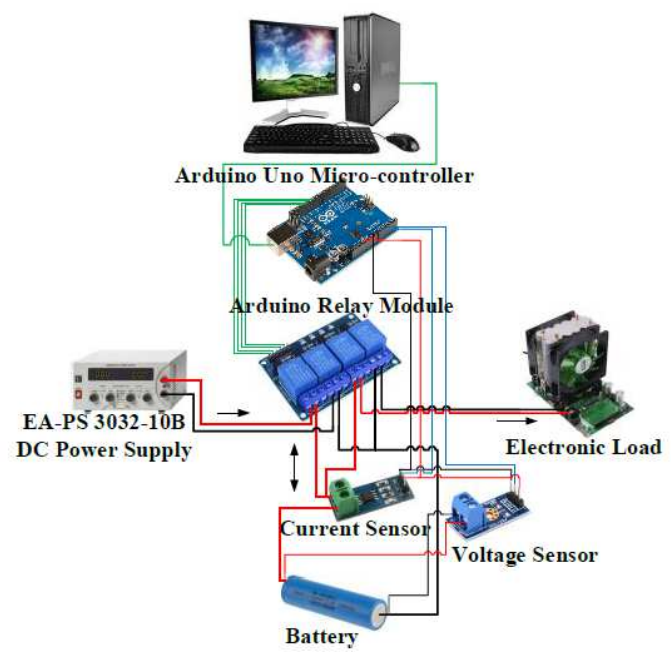

Fig. 2: Experimental set-up for the original concept

\section{Improved test rig design}

To overcome the above challenges with Arduino programming, Laboratory Virtual Instrument Engineering Workbench (LabVIEW) programming language, which was also used by [16], [19], was chosen because it can communicate with the Arduino micro-processor and other instruments simultaneously.

With LabVIEW, it was also easy to re-arrange the order of events permitting automatic switching between battery cycling and capacity testing. Provision of a good platform for developing a graphical user interface with wave form charts and the prospect for developing executable files to help run the software without the need for LabVIEW installation on a computer, were also major considerations.

The limitation on switching current was improved by using the low current switching Arduino relays to switch high current solid-state relays of up to $40 \mathrm{~A}$ and $100 \mathrm{~A}$ for charging and discharging circuits, respectively.

Data logging was achieved through commands that record voltage and current data acquired by the programmable power supply and electronic load. A separate programmable power meter was used on the second channel to record voltage and current data. This was because the manufacturer's charger for the battery on that channel, was not programmable. 
Temperature data was acquired by a TC-08 Pico temperature data logger. All the acquired data was logged on to a text file created on the PC for each cycle.

After the improvements, a 3-channel test rig was developed which was capable of cycling three batteries at the same time. The batteries under test can be of the same or different type. Fig. 3 is a block diagram showing a layout of the 3-channel test rig, Fig. 4 is a user interface for the LabVIEW software and Fig. 5 is the overall set up of the 3channel test rig. When the $<$ Cycle $>$ button on the console shown in Fig. 4 is clicked, the program goes into charging for all the three batteries. When the first battery is fully charged, the battery goes into waiting before being discharged. After discharging the first battery, the other batteries are also discharged sequentially after each of them is verified to be fully charged. The batteries are monitored separately, so each of them goes back into charging mode after a short rest from discharge. When all the three batteries have been discharged, the program goes into the next cycle repeating the process. On reaching a pre-determined interval, the program automatically goes into capacity testing mode where the batteries are discharged at a pre-determined capacity testing C-rate. This periodic capacity testing continues to keep monitoring the battery capacity fade.

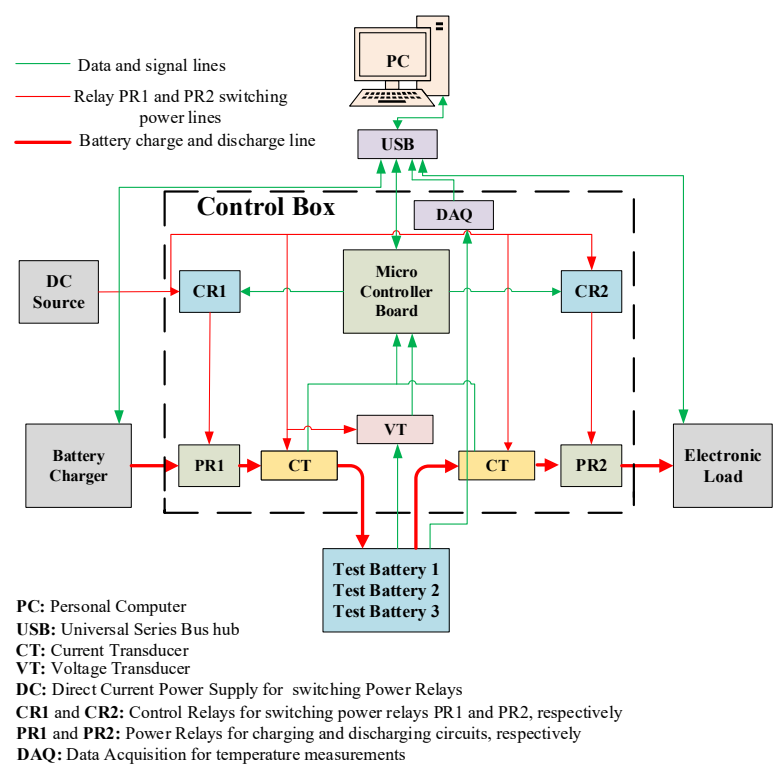

Fig. 3: Block diagram of the 3-channel battery test system

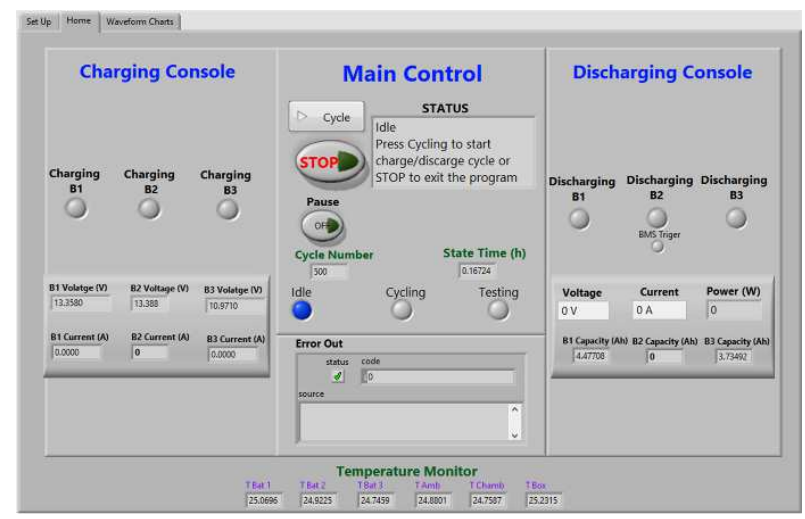

Fig. 4: User interface with displays and control buttons

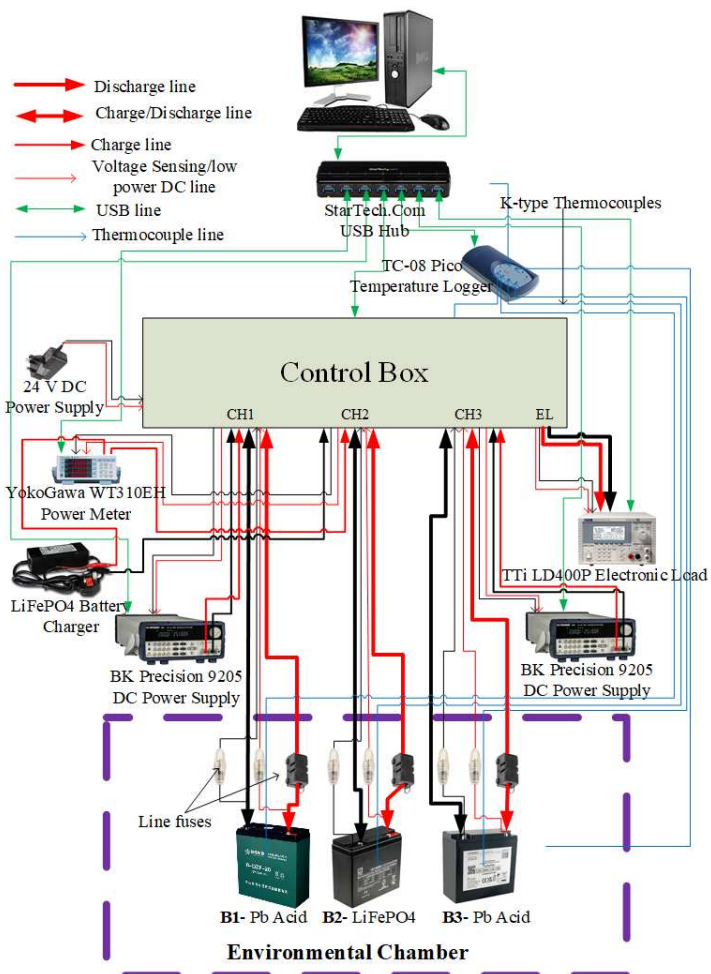

Fig. 5: Overall set-up of the test rig when it was used in practice. The test rig is rated at $60 \mathrm{~V}, 25 \mathrm{~A}, 600 \mathrm{~W}$ for charging and $80 \mathrm{~V}$, $50 \mathrm{~A}, 400 \mathrm{~W}$ for discharge. The environmental chamber provided the mechanism controlling temperature but was separate from the main test rig.

\section{PRACTICAL IMPLEMENTATION}

Before implementation, selected results from the test rig were validated by running similar experiments on another test rig within CREST that was built for testing power hubs with battery energy storage from the Modern Energy Cooking Services (MECS) project. Thereafter, the developed test rig was used to perform life cycle testing for three batteries at constant power to mimic a cooking load that can be experienced from an alternate current Electric Pressure Cooker. The life cycle testing incorporated automatic testing after every 50 cycles. Fig. 6 shows an example of voltage, current and temperature profiles from the test data.

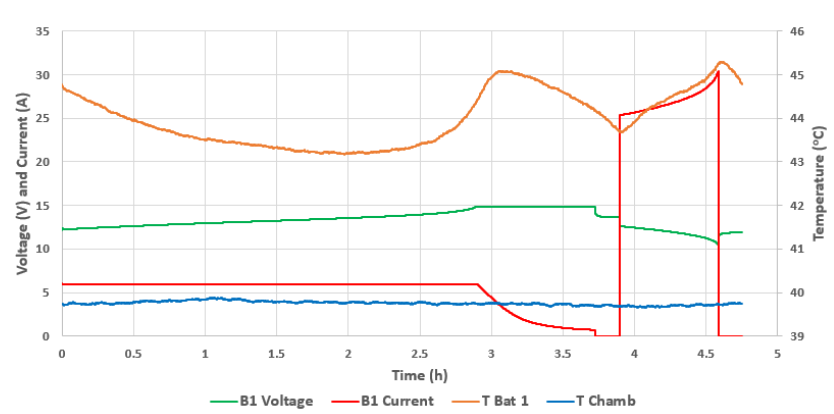

Fig. 6: Sample voltage, current and temperature profiles from a test cycle under constant power discharge.

\section{TEST RIG COST}

This work aimed at developing a low-cost battery test solution that is more affordable to low-income societies while addressing the research gap for improvement of battery performance and longevity. The use of an Arduino for controlling relay switching and sharing of an electronic load among test batteries in the three channels, are considered the 
major cost reduction strategies. In addition, it is envisaged that research institutions in developing countries as well as overseas aid intervention teams, will be able to construct their own units to enable testing in-country. It is assumed the labour to construct a unit will be free of charge or borne by the institution. Self-construction also avoids the layers of profit margins built into commercial units.

The developed test rig rated at $60 \mathrm{~V}, 25 \mathrm{~A}, 600 \mathrm{~W}$ for charging and $80 \mathrm{~V}, 50 \mathrm{~A}, 400 \mathrm{~W}$ for discharging, cost $£ 3,473$ for the purchased materials. This compares favourably with the cost of off the shelf solutions such as a 4-channel Cadex C8000 Advanced Programmable Battery Testing System costing $£ 11,460$ and rated at $10 \mathrm{~A}$ for charge and discharge, $100 \mathrm{~W}$ charging and $80 \mathrm{~W}$ discharging per station [20]. A commercial unit that matched the capabilities of the developed unit would cost considerably more.

\section{FURTHER RESEARCH WORK}

The next step is to replace the solid-state relays with mechanical relays used in automobiles because they are comparatively cheaper and easy to find. The software needs upgrading to improve the automation and to develop executable files so that the software can run on a computer with or without LabVIEW installed on it. In addition, an opportunity will be sought to introduce the test unit to a suitable aid initiative in a developing country and to obtain a sponsor from the battery manufacturing industry.

\section{CONCLUSION}

A novel low-cost battery test rig using a low-cost microcontroller and sharing an electronic load through interlinked solid-state relays, has been developed and used to perform battery life cycle testing. It is believed that this initiative can help to promote battery testing closer to where the batteries are used in the developing world. This would unlock research to improve battery performance and longevity that ultimately will help to improve access to electricity and clean cooking for people in rural communities or in humanitarian situation. The possible challenge expected from this initiative is access to specialist software for continuous software upgrade, but continued partnerships with collaborating institutions from the developing world, can be a possible solution.

\section{ACKNOWLEDGMENT}

This work has been achieved with support from MECS and JUICE Projects in Loughborough University, Commonwealth Scholarship Commission and Mzuzu University.

\section{REFERENCES}

[1] M. Caniato, D. Carliez, and A. Thulstrup, "Challenges and opportunities of new energy schemes for food security in humanitarian contexts: A selective review," Sustain. Energy Technol. Assessments, vol. 22, pp. 208-219, 2017, doi: 10.1016/j.seta.2017.02.006.

International Energy Agency, "Global population without access to electricity by region, 2000-2021 - Charts - Data \& Statistics IEA." https://www.iea.org/data-and-statistics/charts/globalpopulation-without-access-to-electricity-by-region-2000-2021-2 (accessed Oct. 29, 2021).

[3] P. M. Dauenhauer, D. Frame, A. Eales, S. Strachan, S. Galloway, and H. Buckland, "Sustainability evaluation of community-based, solar photovoltaic projects in Malawi," Energy. Sustain. Soc., vol. 10, no. 1, 2020, doi: 10.1186/s13705-020-0241-0.

[4] International Energy Agency, "Universal Access to Sustainable
Energy Will Remain Elusive Without Addressing Inequalities News - IEA," 2021. https://www.iea.org/news/universal-accessto-sustainable-energy-will-remain-elusive-without-addressinginequalities (accessed Jul. 27, 2021).

[5] J. Barbieri, F. Riva, and E. Colombo, "Cooking in refugee camps and informal settlements: A review of available technologies and impacts on the socio-economic and environmental perspective," Sustain. Energy Technol. Assessments, vol. 22, pp. 194-207, Aug. 2017, doi: 10.1016/J.SETA.2017.02.007.

[6] S. Batchelor, E. Brown, J. Leary, N. Scott, A. Alsop, and M. Leach, "Solar electric cooking in Africa: Where will the transition happen first?," Energy Res. Soc. Sci., vol. 40, no. September 2017, pp. 257-272, 2018, doi: 10.1016/j.erss.2018.01.019.

[7] E. Brown, J. Leary, G. Davies, S. Batchelor, and N. Scott, "eCook: What behavioural challenges await this potentially transformative concept?," Sustain. Energy Technol. Assessments, vol. 22, pp. 106-115, 2017, doi: 10.1016/j.seta.2017.02.021.

[8] A. Gulagi, D. Bogdanov, and C. Breyer, "The Demand for Storage Technologies in Energy Transition Pathways Towards $100 \%$ Renewable Energy for India," Energy Procedia, vol. 135, pp. 3750, 2017, doi: 10.1016/j.egypro.2017.09.485.

[9] D. Parra, M. Swierczynski, D. I. Stroe, S. A. Norman, A. Abdon, J. Worlitschek, T. O’Doherty, L. Rodrigues, M. Gillott, X. Zhang, C. Bauer, and M. K. Patel, "An interdisciplinary review of energy storage for communities: Challenges and perspectives," Renew. Sustain. Energy Rev., vol. 79, no. May 2016, pp. 730-749, 2017, doi: 10.1016/j.rser.2017.05.003.

[10] B. Diouf and R. Pode, "Potential of lithium-ion batteries in renewable energy," Renew. Energy, vol. 76, pp. 375-380, Apr. 2015, doi: 10.1016/J.RENENE.2014.11.058.

[11] B. Bogno, J.-P. Sawicki, T. Salame, M. Aillerie, F. Saint-Eve, O. Hamandjoda, and B. Tibi, "Improvement of safety, longevity and performance of lead acid battery in off-grid PV systems," Int. J. Hydrogen Energy, vol. 42, no. 5, pp. 3466-3478, Feb. 2017, doi: 10.1016/j.ijhydene.2016.12.011.

[12] E. M. Krieger, J. Cannarella, and C. B. Arnold, "A comparison of lead-acid and lithium-based battery behavior and capacity fade in off-grid renewable charging applications," Energy, vol. 60, pp. 492-500, 2013, doi: 10.1016/j.energy.2013.08.029.

[13] G. J. May, A. Davidson, and B. Monahov, "Lead batteries for utility energy storage: A review," J. Energy Storage, vol. 15, pp. 145-157, 2018, doi: 10.1016/j.est.2017.11.008.

[14] M. Weiss, "The Fundamentals of Battery Test Webinar," NH Research Webnar. https://myemail.constantcontact.com/Thankyou-for-attending-The-Fundamentals-of-Battery-Test-

Webinar.html?soid=1113244869046\&aid=5bxJPZSpRs4 (accessed Nov. 21, 2020)

[15] C. Carballo, M. Gonzalez, J. C. Alvarez, and C. Blanco, "Computerized system for testing batteries in full controlled environment," in Conference Record - IEEE Instrumentation and Measurement Technology Conference, 2000, vol. 1, pp. 395-399. doi: $10.1109 /$ imtc.2000.846893.

[16] J. C. Viera, M. Gonzalez, C. Carballo, and C. Blanco, "An intelligent instrumentation system for testing fast-charging process in high-capacity batteries," in Conference Record - IEEE Instrumentation and Measurement Technology Conference, 2000, vol. 3, pp. 1372-1376. doi: 10.1109/imtc.2000.848700.

[17] R. Ramdan, M. B. Mohamed, A. N. Abdalla, and M. Rauf, "Design and develop automatic battery cyclic tester," in 2013 The International Conference on Technological Advances in Electrical, Electronics and Computer Engineering, TAEECE 2013, 2013, pp. 61-65. doi: 10.1109/TAEECE.2013.6557196.

[18] A. Buchroithner, P. Haidl, C. Birgel, T. Zarl, and H. Wegleiter, "Design and experimental evaluation of a low-cost test rig for flywheel energy storage burst containment investigation," Appl. Sci., vol. 8, no. 12, p. 2622, Dec. 2018, doi: 10.3390/app8122622.

[19] C. Carballo, M. Gonzalez, J. C. Alvarez, and C. Blanco, "A computerized system for testing batteries in full controlled environment," Conf. Rec. - IEEE Instrum. Meas. Technol. Conf., vol. 1, pp. 395-399, 2000, doi: 10.1109/IMTC.2000.846893.

[20] McKay Europ Ltd, "Cadex C8000 Advanced Programmable Battery Testing System." https://www.mckayeurope.com/store/Cadex-C8000-AdvancedProgrammable-Battery-Testing-System-p207650804 (accessed Jul. 30, 2021). 